\title{
Experimental Study on the Effective Utilization of Reserves in Tight Sandstone Gas Reservoirs and Their Applications
}

\author{
Jie Zhang, ${ }^{1,2}$ Feifei Fang $\mathbb{D}^{3}{ }^{3}$ Weijun Shen $\mathbb{D}^{1,4}$ Huaxun Liu, ${ }^{2,5}$ Shusheng Gao, ${ }^{2,5}$ \\ and Liyou Ye $\mathrm{Y}^{2,5}$ \\ ${ }^{1}$ School of Engineering Science, University of Chinese Academy of Sciences, Beijing 100049, China \\ ${ }^{2}$ Department of Porous Flow \& Fluid Mechanics, PetroChina Research Institute of Petroleum Exploration \& Development, \\ Langfang 065007, China \\ ${ }^{3}$ School of Petroleum Engineering, Chongqing University of Science and Technology, Chongqing 401331, China \\ ${ }^{4}$ Key Laboratory for Mechanics in Fluid Solid Coupling Systems, Institute of Mechanics, Chinese Academy of Sciences, \\ Beijing 100190, China \\ ${ }^{5}$ Research Institute of Petroleum Exploration \& Development, PetroChina, Beijing 100083, China
}

Correspondence should be addressed to Feifei Fang; fangfeifei@cqust.edu.cn and Weijun Shen; wjshen763@imech.ac.cn

Received 25 May 2020; Revised 14 September 2020; Accepted 19 October 2020; Published 23 November 2020

Academic Editor: Wen-Dong Wang

Copyright @ 2020 Jie Zhang et al. This is an open access article distributed under the Creative Commons Attribution License, which permits unrestricted use, distribution, and reproduction in any medium, provided the original work is properly cited.

\begin{abstract}
The effective utilization of reserves in tight sandstone reservoirs is one of the major concerns in terms of the development of tight sandstone gas reservoirs. However, the characteristics of reserve utilization are not fully understood, and many uncertainties still exist in the process. For this purpose, long cores on the Su 6 block of Sulige tight sandstone gas field in China were selected, and a multipoint embedded measurement system was established to study the characteristics of effective reserve utilization. Then, the effects of the related reservoir properties and production parameters were investigated. Based on the similarity theory, the effective conversion relationship between the physical experiment and the actual field production was established. The results showed that the pressure distribution in the exploitation of tight gas reservoir is nonlinear, and water cut in the reservoir will hinder the effective utilization of reserves. The lower the reservoir permeability, the larger the negative effect of water on reservoir utilization. Lower gas production rate and higher original pressure are associated with a smoother drawdown curve, which results in larger reserve utilization. The moving boundary expands with time, and its initial propagation velocity increase and then decrease. Additionally, the water cut in the reservoir can delay the spread of moving boundary propagation. The experimental results are consistent with the actual results of the field production by the similarity criterion, which can reflect and predict the production performance in tight gas reservoirs effectively. These results can provide a better understanding of reservoir pressure distribution and effective utilization of reserves to optimize the gas recovery and development benefit in tight sandstone gas reservoirs.
\end{abstract}

\section{Introduction}

Tight sandstone gas reservoirs are widely distributed throughout the world with huge resource potential, which is playing an increasingly important role among energy sources [1,2]. Up till 2019, the discovered tight sandstone gas field is more than 70 and the total amount of estimated recoverable is more than $45 \times 10^{13} \mathrm{~m}^{3}$ [3]. According to the statistics, the recoverable reserves of tight sandstone gas in
China are about $13.4 \times 10^{8} \mathrm{~m}^{3}$, which accounts for more than $50 \%$ of the total natural gas reserves in the country. Therefore, the efficient development of tight sandstone gas is of great significance to the implementation of China's natural gas strategy [4]. At present, most of the tight sandstone gas reservoirs belong to lithologic gas reservoirs which are formed under the microstructure background, and they are characterized by small-scale, low reserve abundance, large amplitude change in production, and more development 
difficulties $[5,6]$. Due to the geological characteristics with low porosity, low permeability, and high water saturation, as well as the development characteristics of threshold pressure gradient, Klinkenberg effect, and stress sensitivity, the propagation law of the pressure disturbance in tight sandstone reservoirs significantly differs from conventional gas reservoirs [7, 8]. Moreover, the seepage laws in tight sandstone reservoirs also differ from Darcy's law. The characteristics of pressure propagation and pressure distribution in tight sandstone reservoirs are the direct reflection on the effective utilization range and utilization degree of the reservoir, which is also the theoretical basis for cognizing geofluid flow characteristics, gas production calculation, and well testing in gas reservoirs [9]. Therefore, there is great significance to understand the effective utilization of reserves for gas productivity and optimize the effective development in tight gas reservoirs.

In the last few decades, there has been a surge of interest in the characteristics of fluid flow and reservoir pressure distribution in the low permeability reservoirs [10]. Based on comprehensive consideration of threshold pressure gradient, nonlinear flow, and dynamic boundary effects, some scholars have established a large number of the percolation models of low-permeability reservoirs. Pascal analyzed the transient flow in a one-dimensional model with the threshold pressure gradient and derived the approximate analytical solution [11]. Feng and Ge [12] established the mathematical model of unsteady non-Darcy flow in the dual-medium reservoir and analyzed the change of bottom hole pressure in the different exploitation process. Wattenbarger et al. [13] analyzed the production decline curve analysis of linear flow into fractured tight gas wells. Considering the threshold pressure gradient and moving boundary factors, Deng and Liu [14] proposed a mathematical model of nonlinear steady flow and unsteady percolation in low permeability reservoirs and derived the reservoir pressure distribution of two percolation models. Hsieh et al. [15] used both analytical and numerical methods to estimate the pressure disturbance area from a producing well in an infinite reservoir. Feng et al. [16] established a mathematical model of nonlinear percolation in lowpermeability gas reservoirs which considered the threshold pressure gradient. Wang et al. [17] derived a new analytical expression of pressure distribution and moving boundary propagation by approximate solving the mathematical model of nonlinear radial unstable fluid flow, which involved threshold pressure gradient and moving boundary using the integration method. $\mathrm{Ji}$ and $\mathrm{He}$ [18] established a non-Darcy radial percolation model for ultralow permeability reservoirs under constant flow and constant flow conditions, which considers the threshold pressure gradient. Nobakht and Clarkson $[19,20]$ studied the linear flow of fractured wells in tight gas reservoirs under constantflowing-pressure boundary conditions and obtained the corresponding expressions of detection boundary propagation. Based on the trilinear flow model, Huang et al. [21] established a new analytical model of a multifractured horizontal well to recognize formation properties and forecast the dynamics of pressure and the production in tight gas reservoirs. Besides, there are some studies conducted in the physical experiments, and $\mathrm{Hu}$ et al. [22] conducted gas perco- lation experiments to understand the changes in reservoir pressures during tight gas reservoir exploitation under the conditions of homogeneous cores. Based on the similarity theory of heterogeneous reservoir, $\mathrm{Yu}$ et al. [23] used lowpermeability physical simulation by artificial core plate model to study on the seepage flow patterns in heterogeneous low permeability reservoir. However, although there have been a lot of numerical simulations studies, most of these studies have generally been restricted to the idealized conditional, which cannot truly represent the pressure disturbance propagation and the reserve utilization in the actual formation. Concerning physical simulation studies, the length of core commonly used is generally only $5-8 \mathrm{~cm}$; thus, accordingly, the effect of end surface is obvious [24]. The existing long core experiments usually arrange the growing cores or multicores in series through the permeability harmonic average method, and there is a great error compared with actual formation [25, 26].

In this study, the multipoint embedded measurement system was established, and the $30 \mathrm{~cm}$ long core of the Sulige tight sandstone gas fields was selected by outcrop coring to simulate the variation law of reservoirs pressure in the different exploitation processes. The propagation characteristics of pressure disturbance and reserve utilization of tight sandstone gas reservoirs during the exploitation process were studied, and the effects of the related reservoir properties and production parameters such as permeability, pressure, water saturation, and gas production were investigated. Based on the above study, the effective conversion relationship between the physical experiment and the actual field production was established by the dimensional analysis, and the experimental results were transformed into the actual field production. These results can provide a better understanding of reservoir pressure distribution and effective utilization of reserves for improving the gas recovery and development benefit in tight gas reservoirs.

\section{Experimental Samples and Methods}

2.1. Experimental Samples. Sulige gas field, the biggest tight sand gas reservoir in China, is a gentle west-leaning monocline located in the Yishan slope of the Ordos Basin, which is a monoclinic structure inclined from northeast to southwest with an exploration area of about $4.0 \times 10^{4} \mathrm{~km}^{2}$ [25]. The Su 6 block is located in the middle of the Sulige gas field in the Ordos Basin, and it is one of the most favorable natural gas enrichment and key development blocks in the Sulige gas field.

In the previous studies, physical simulation experiments often use conventional cores with a length of $5-8 \mathrm{~cm}$ which can result in the effect of end surface. Although long core formed by splicing can weaken the effect of end surface, it differs significantly from the actual formation. Constrained by coring technology and coring equipment, conventional coring of long cores is very difficult. In this study, $30 \mathrm{~cm}$ lone core samples are collected by outcrop coring from the Su 6 block of the Sulige tight sandstone gas field. Then, three cores with permeability values of $1.49 \times 10^{-3} \mu \mathrm{m}^{2}, 0.32 \times 10^{-3} \mu \mathrm{m}^{2}$, and $0.028 \times 10^{-3} \mu \mathrm{m}^{2}$ are selected to understand the propagation characteristics of pressure disturbance and reserve utilization of tight sandstone gas reservoirs during the 
TABLE 1: Basic properties of tight sandstone cores.

\begin{tabular}{lcccc}
\hline Core no. & Core type & Core size $(\mathrm{cm})($ length $\times$ diameter $)$ & Permeability $\left(10^{-3} \mu \mathrm{m}^{2}\right)$ & Porosity $(\%)$ \\
\hline Su1 & Low permeability & $30 \times 3.76$ & 1.49 & 14.6 \\
Su2 & Ultra-low permeability & $30 \times 3.72$ & 0.32 & 11.7 \\
Su3 & Tight & $30 \times 3.77$ & 0.028 & 8.8 \\
\hline
\end{tabular}

exploitation. The basic properties of the tight sandstone cores used in this study are shown in Table 1.

Tight sandstone gas reservoirs are characterized by low permeability, high heterogeneity, and high water saturation $[22,27]$. During the depletion-drive development, the reservoir pressure gradually decreases, and the pressure within the gas well drainage radius will exhibit a decreasing drawdown curve from the distal reservoir to the proximal. The physical properties and gas production rate of the reservoir are diverse; thus, the pressure drop profiles in the different development phases are also different, which reflects the imbalance in the utilization of reserves. According to the propagation characteristics of pressure disturbance and reserve utilization of tight sandstone gas reservoirs, the effects of the related reservoir properties and production parameters such as reservoir permeability, original pressure, water saturation, and gas production rate were considered, and the experiments of the effective utilization of reserves conducted on different conditions are summarized in Table 2.

2.2. Experimental Methods. In the study, the experimental system of multipoint embedded measurement in the gas reservoir development is illustrated in Figure 1, which was composed of a gas boosting section, core simulation section, and data acquisition section. The unique feature of this experimental system is that in addition to the two pressure points at the inlet and outlet ends, there are also three pressure points evenly distributed in the sidewall of the core holder. The pressure sensor corresponding to each pressure measuring point has an independent rigid collecting channel in which the apex has installed a filter. The fore-end of the pressure sensor is placed inside the core through the sealing isolating device of the pressure-receiving device, which can accurately measure the pressure changes at different positions on the core section during the gas reservoir development. The pressure point recording interval is $2 \mathrm{~s}$. Through the data processing device, the pressure profiles of different development phases can be established according to the measured pressure, and determine reservoir pressure propagation and pressure distribution characteristics finally.

The following experimental processes are set up to simulate the effective utilization of reserves in tight sandstone gas reservoirs under different conditions: (1) According to the experimental scheme, the core samples were chosen (for the aqueous experiment, the irreducible water saturation was established on the core by the gas-drive method). Drill a radial hole in the core and put the core in the core holder, and then place the rigid collecting channel of the pressure sensor in the corresponding radial hole. (2) The nitrogen was previously pressurized to $20 \mathrm{MPa}$ by gas booster pump
TABle 2: Different experiments for the reservoir utilization conducted.

\begin{tabular}{lccc}
\hline $\begin{array}{l}\text { Experimental } \\
\text { scheme }\end{array}$ & $\begin{array}{c}\text { Core } \\
\text { No. }\end{array}$ & $\begin{array}{c}\text { Original pressure } \\
(\mathrm{MPa})\end{array}$ & $\begin{array}{c}\text { Gas production } \\
\text { rate }(\mathrm{mL} / \mathrm{min})\end{array}$ \\
\hline 1 & Su1 & 20 & $2000,6000,10000$ \\
2 & Su2 & 20 & $500,1000,1500$ \\
3 & Su3 & 20 & $100,300,500$ \\
4 & Su3 & 25 & $100,300,500$ \\
\hline
\end{tabular}

and stored in the high-pressure vessel. After the confining pressure was increased to $30 \mathrm{MPa}$, open the safety valve and the control valve 2, and the core samples was filled with high-pressure nitrogen. Then, the core samples were saturated with a set saturation pressure secondarily by a gas booster pump. When the pressure distribution inside the core was uniform, remove the high-pressure gas source and prepare to start the experiment. (3) Open the control valve 3 and release the gas at a constant gas production rate by regulating valve 3 at the outlet end during the initial stage. The regulator valve 3 was opened to release gas from the outlet end of the core holder, and the outlet end flow rate was controlled by the regulating valve 3 . After the outlet pressure was reduced to the abandonment pressure $5 \mathrm{MPa}$, the experiment terminated, and the abandonment pressure $P_{a}$ is calculated using the empirical formula of the constant volume reservoir, $P_{a}=(0.7 \sim 0.5) P_{i} Z_{a} / Z_{i}$. (4) At the end of the experiment, the drawdown curves were made with the experimental data. Then, the characteristics of drawdown curves and the effect of the different factors on the utilization of tight sandstone reservoirs were analyzed comprehensively. During the experiment, the core system of saturated high-pressure nitrogen was closed completely, and there was no other external energy supply. There is a great difference in the compressibility between the gas phase and the water phase, and thus, it could be ideally considered that the energy source of the product gas was the gas expansion caused by the reservoir pressure drop.

2.3. Basic Theory. The material balance equation has long been recognized as one of the basic tools for interpreting and predicting reservoir performance, which was presented by Schilthuis [29, 30]. The equation of the closed dry gas reservoir can be written as follows:

$$
G B_{g i}=\left(G-G_{p}\right) B_{g}
$$

where $G$ is the initial gas-cap gas; $G_{p}$ is the cumulative gas produced; $B_{g i}$ is the initial gas formation volume factor; $B_{g}$ 


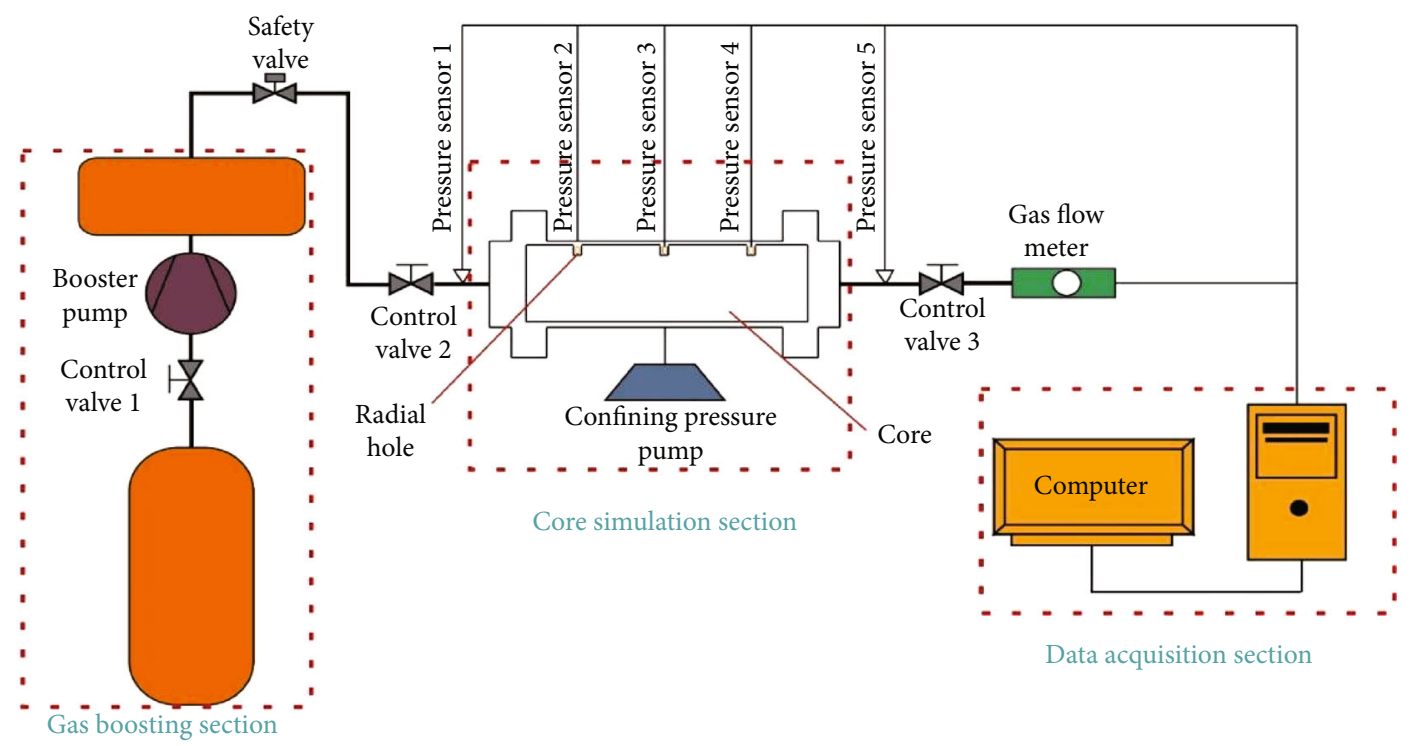

FIGURE 1: Measurement of multipoint embedded measurement in gas reservoir development.

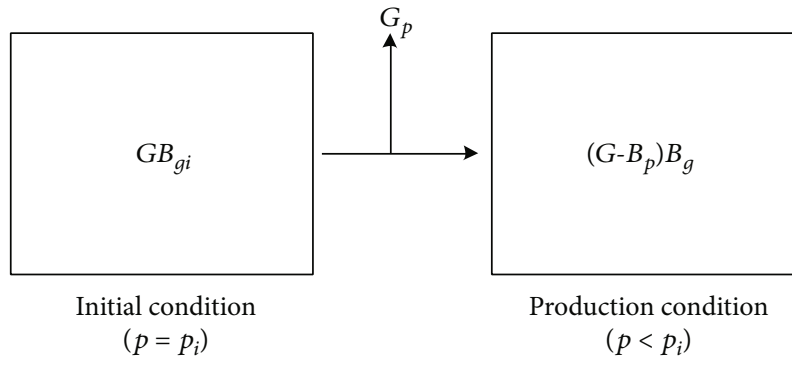

Figure 2: Tank model concept of the material balance equation [28].

is the gas formation volume factor; $G B_{g i}$ is the reservoir volume filled with gas under the initial reservoir pressure, and it is the core pore volume for the dry core, while the waterbearing core is that the core pore volume minus the irreducible water volume; $\left(G-G_{p}\right) B_{g}$ is the reservoir volume filled with gas at the pressure $P_{i}$ after gas production, which is illustrated in Figure 2.

By substituting the ratio of the gas formation volume factor under initial condition and production $\left(B_{g i /} B_{g}=Z P_{i}\right)$ into the Equation (1), thus, Equation (1) can be rewritten and expressed as

$$
\frac{P}{Z}=\frac{P_{i}}{Z_{i}}-\frac{P_{i}}{Z_{i} G} G_{p} .
$$

From Equation (2), it can be seen that the graph of $P / Z$ versus $G_{p}$ is a straight line if the reservoir is a closed boundary. Based on the curve of $P / Z$ versus $G_{p}$ in the depletiondrive development of tight sandstone gas reservoir, the dynamic reserve $G$ can be obtained by the intercept.

In this study, the gas production rate $(q)$ and the cumulative gas $\left(G_{p}\right)$ can be measured, and the degree of reserve
TABLE 3: Changes of related parameters between dry core and aqueous cores.

\begin{tabular}{lcccc}
\hline $\begin{array}{l}\text { Core } \\
\text { No. }\end{array}$ & $\begin{array}{c}\text { Permeability } \\
\left(10^{-3} \mu \mathrm{m}^{2}\right)\end{array}$ & $\begin{array}{c}\text { Aqueous cores } \\
\text { Water } \\
\text { saturation }\end{array}$ & $\begin{array}{c}\text { Permeability } \\
\left(10^{-3} \mu \mathrm{m}^{2}\right)\end{array}$ & $\begin{array}{c}\text { Permeability } \\
\text { loss }\end{array}$ \\
\hline Su1 & 1.49 & $38 \%$ & 0.86 & $46 \%$ \\
Su2 & 0.32 & $43 \%$ & 0.15 & $61 \%$ \\
Su3 & 0.028 & $48 \%$ & 0.022 & $21 \%$ \\
\hline
\end{tabular}

recovery can be calculated from the cumulative gas and the dynamic reserve,

$$
R=\frac{G_{p}}{G} .
$$

Define the recovery at a point in the core segment as $\left(1-Z_{i} P / Z P_{i}\right)$, where $P$ is selected as the pressure at that point,

$$
R^{\prime}=\left(1-\frac{Z_{i} P}{Z P_{i}}\right) \text {. }
$$

\section{Results and Discussion}

3.1. Effect of Reservoir Permeability and Water Saturation. The gas driving method was often used to establish the water saturation of the core. However, it is more difficult to establish water saturation for the $30 \mathrm{~cm}$ long core in the experiment. Here, the dry and irreducible water conditions were compared to study the effect of water saturation on reserve utilization in tight gas reservoirs. Based on the gas driving method, the irreducible water saturation was established for the cores, and the changes of related parameters between dry core and aqueous cores were shown in Table 3. According to the experimental scheme, the physical experiments of 

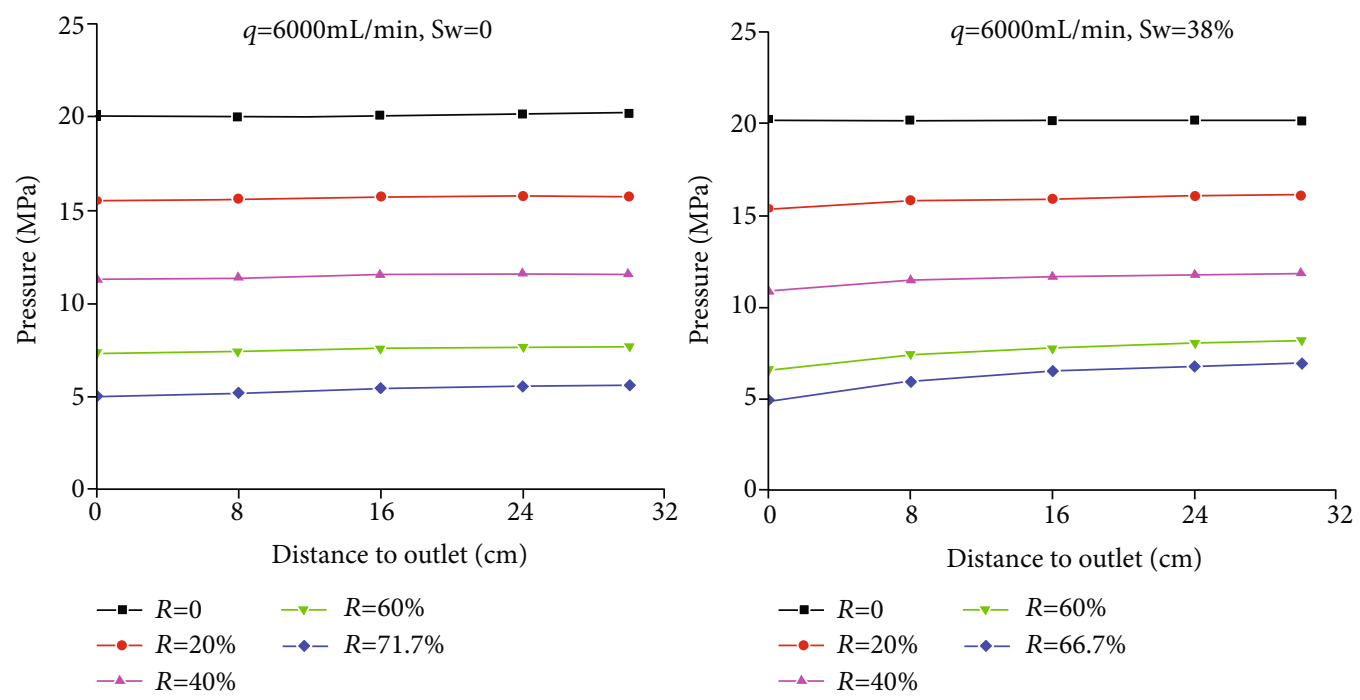

FIgURE 3: Comparisons of reserve utilization in the Sul core under the dry and irreducible water conditions.
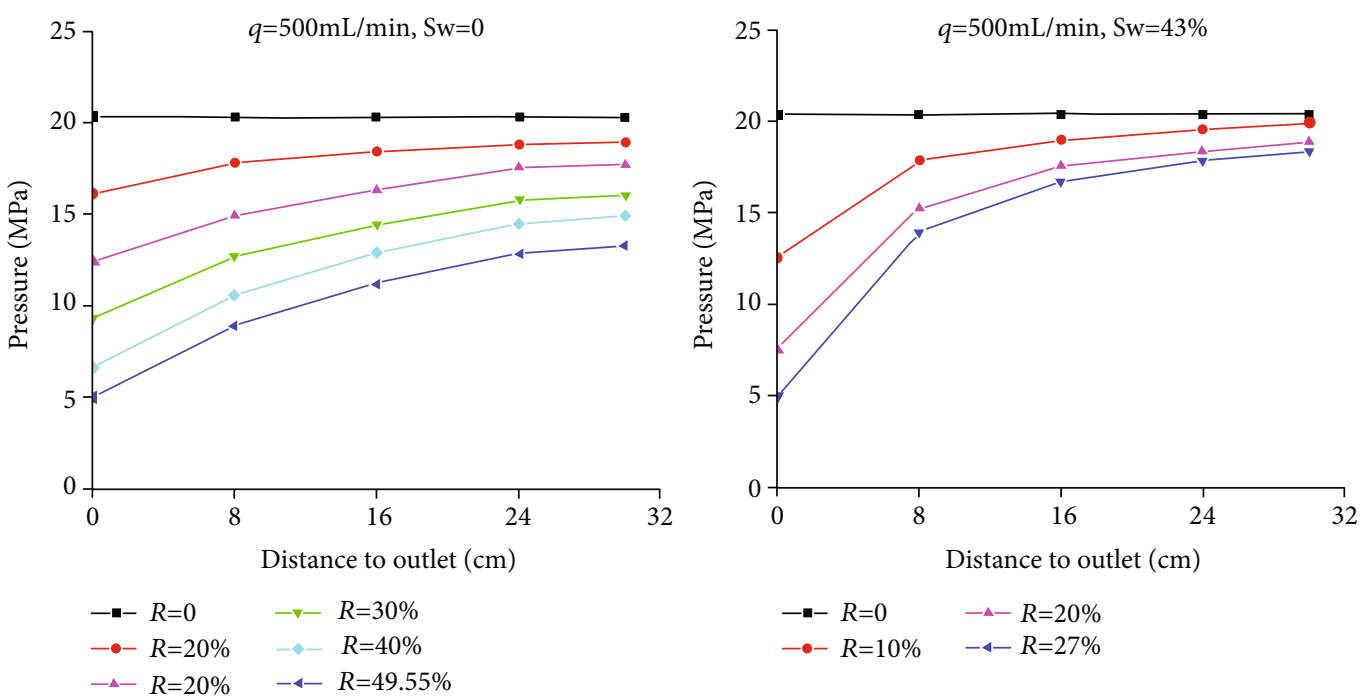

FIgURE 4: Comparisons of reserve utilization in the Su2 core under the dry and irreducible water conditions.

different permeability sandstone cores in the exploitation were conducted, and the propagation characteristics of pressure disturbance and reserve utilization were studied by the system of multipoint embedded measurement.

For the formation of a sandstone reservoir with permeability greater than $1 \times 10^{-3} \mu \mathrm{m}^{2}$ represented by Sul core, the reserve utilization under the dry and irreducible water conditions is illustrated in Figure 3. The fluid percolation channel is mainly capillary pore throat $(0.1 \mu \mathrm{m}<r<1 \mu \mathrm{m})$ and supercapillary pore throat $(r>1 \mu \mathrm{m})$, and the resistance of single-phase gas to flow in the core is very small. From the results of the experiment, the internal pressure of the core is basically the same, with evenly decreasing, and the drawdown pressure is extremely small. The drawdown curve is approximately a straight line, and there is almost no pressure cone of depression. The average pressure in the dynamic control area is low when the core outlet reaches the abandonment pressure, and the reservoir is very well utilized. When the gas production rate is $6000 \mathrm{~mL} / \mathrm{min}$, the experiment is carried out for $8.23 \mathrm{~min}$, and then, the pressure at the outlet reaches the abandonment pressure. The pressure at the inlet and outlet of the dry core is $5.66 \mathrm{MPa}$ and $5.03 \mathrm{MPa}$, respectively. The drawdown pressure is $0.63 \mathrm{MPa}$, and the ultimate recovery is $71.7 \%$. When the reservoir contains irreducible water, the irreducible water is present in the form of a water film on the surface of the reservoir pore throat. The thickness of the water film is very small relative to the radius of the pore throat, so the influence on the gas seepage is negligible. In the study, the experiment was finished in $4.13 \mathrm{~min}$, and the drawdown pressure and the ultimate recovery are $0.99 \mathrm{MPa}$ and $66.7 \%$, respectively.

For the formation of a sandstone reservoir with the permeability of $0.1 \sim 1 \times 10^{-3} \mu \mathrm{m}^{2}$ represented by Su2 core, the reserve utilization under the dry and irreducible water conditions is illustrated in Figure 4. The fluid percolation channel is mainly microcapillary pore throat $(0.01 \mu \mathrm{m}<r<0.1 \mu \mathrm{m})$ 

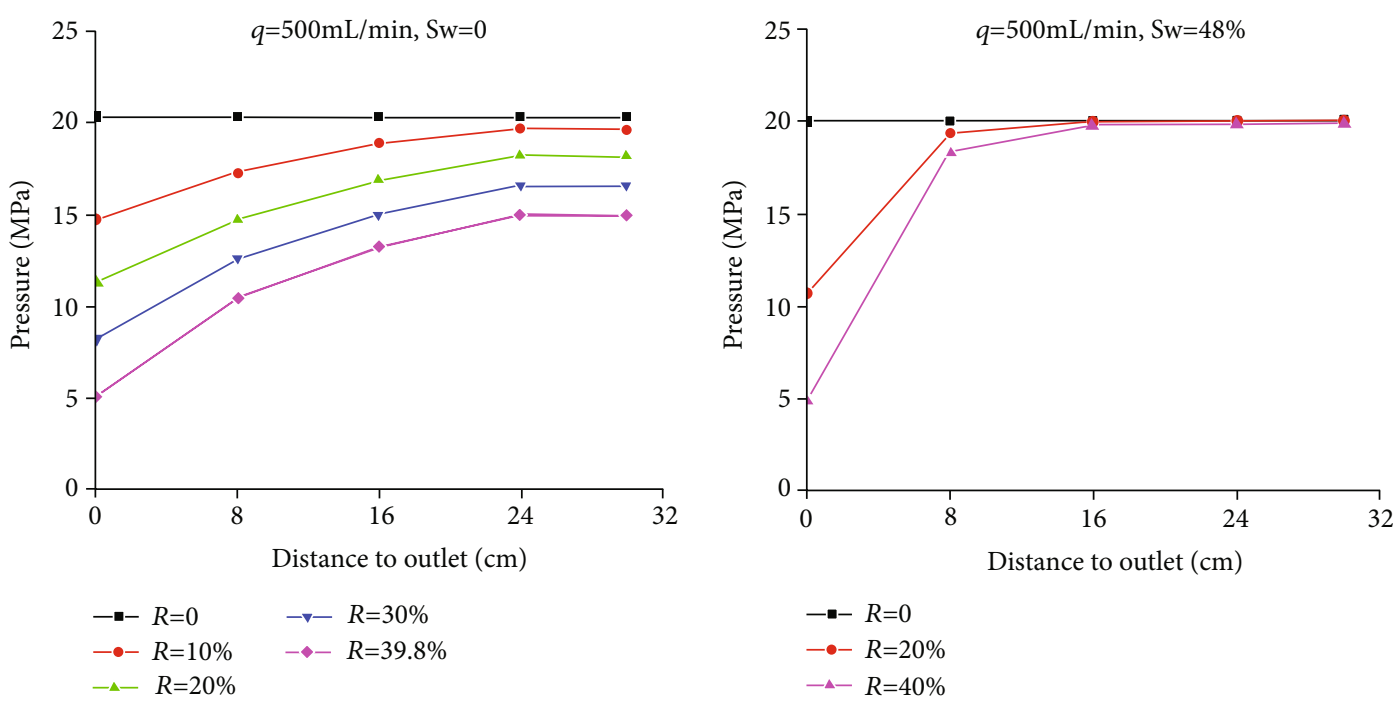

FIgURE 5: Comparisons of reserve utilization in the Su3 core under the dry and irreducible water conditions.

and capillary pore throat. From the result, it can be seen that there exists the obvious percolation resistance when the gas flows through in the core. The drawdown curve is nonlinear, which shows the pressure cone of depression. When the pressure drop reaches the end of the core, the pressure drop at each point decreases uniformly with the increase of time and reaches the pseudosteady state. When the gas production rate is $500 \mathrm{~mL} / \mathrm{min}$, the experiment is carried out for $5.38 \mathrm{~min}$, and the outlet reaches the abandonment pressure. At the end of the experiment, the drawdown pressure is $8.29 \mathrm{MPa}$, and the ultimate recovery of the dry core is $49.55 \%$. The reservoir contains the irreducible water, and the thickness of the irreducible water film is not negligible compared with the radius of the main control throat. The existence of the water film occupies the effective pore throat of the reservoir, and it reduces the effective pore throat radius and increases the percolation resistance to affect the effective gas flow, which results in a larger drawdown pressure than in the nonaqueous state to maintain the same gas production rate. When the core contains irreducible water, the experiment was finished in $1.67 \mathrm{~min}$; the drawdown pressure and the ultimate recovery are $13.32 \mathrm{MPa}$ and $27 \%$, respectively.

For the formation of a sandstone reservoir with permeability less than $1 \times 10^{-3} \mu \mathrm{m}^{2}$ represented by Su3 core, the reserve utilization under the dry and irreducible water conditions is illustrated in Figure 5. The microcapillary pore throat and nanopore throat $(r<0.1 \mu \mathrm{m})$ play the main control role in the permeability of the formation. Compared with Su2, Su3 has a smaller radius of the main control hole throat, and the gas is more resistant to percolation in such reservoirs. The drawdown curve is more nonlinear, and the pressure cone of depression is more obvious. The reserves can be utilized near the outlet while the reserves are utilized very poorly at a distance from the outlet. When the gas production rate is $500 \mathrm{~mL} / \mathrm{min}$, the experiment is carried out for $8 \mathrm{~min}$, and the outlet reaches the abandonment pressure. At the end of the experiment, the drawdown pressure is $9.91 \mathrm{MPa}$, and the degrees of reserve recovery degrees in the pressure measurement points $1,2,3,4$, and 5 are $24.2 \%, 24 \%, 32.4 \%, 46.1 \%$, and $73.9 \%$, respectively, and the degree of reserve recovery in the dry core is $49.55 \%$. When the reservoir contains irreducible water, the main pore throat radius is smaller than that of the ultralow permeability sandstone reservoir, and the rock pore surface has a stronger ability to bind water molecules. Both the irreducible water saturation and the water film thickness are larger, and the thickness of the irreducible water film is even in the same order of magnitude as the radius of the pore throat because the influence of waterbearing gas percolation is greater. At the end of the experiment, the pressure near the inlet hardly decreased, and the reserves were basically not utilized. The pressures corresponding to the pressure measuring points $1,2,3,4$, and 5 were $19.90 \mathrm{MPa}, 19.88 \mathrm{MPa}, 19.83 \mathrm{MPa}, 18.36 \mathrm{MPa}$, and 4.92 $\mathrm{MPa}$, respectively, and reserve utilization in the pressure measurement points was $1.88 \%, 2 \%, 2.40 \%, 8.56 \%$, and $74.31 \%$, respectively. The drawdown pressure reaches $14.98 \mathrm{MPa}$, while the reservoir ultimate recovery is only $8.40 \%$, and the ultimate recovery is reduced by $31.4 \%$ compared with the dry core.

3.2. Effect of Initial Pressure. The original pressure of tight sandstone gas reservoir is varied in different areas, which affects the ultimate recovery $[31,32]$. In this study, the Su3 core with irreducible water was chosen to study the effects of different initial reservoir pressures in the reservoir utilization. The gas production rate and original pressure were $100 \mathrm{~mL} / \mathrm{min}, 20 \mathrm{MPa}$, and $25 \mathrm{MPa}$, respectively, which was shown in Figure 6. When the original pressure of the core was $20 \mathrm{MPa}$, the gas production rate was $100 \mathrm{~mL} / \mathrm{min}$, and the experiment was completed in $20.07 \mathrm{~min}$. The pressures corresponding to the pressure measurement point $1,2,3,4$, and 5 were $11.81 \mathrm{MPa}, 11.59 \mathrm{MPa}, 11.36 \mathrm{MPa}, 8.54 \mathrm{MPa}$, and $5 \mathrm{MPa}$, respectively. The drawdown pressure was $6.81 \mathrm{MPa}$ at the end of the experiment, and the ultimate recovery was $48.3 \%$. While the initial saturation pressure was $25 \mathrm{MPa}$, the gas production rate was $100 \mathrm{~mL} / \mathrm{min}$, and the experiment was carried out for $34.12 \mathrm{~min}$. The pressures corresponding to the pressure measurement points $1,2,3$, 

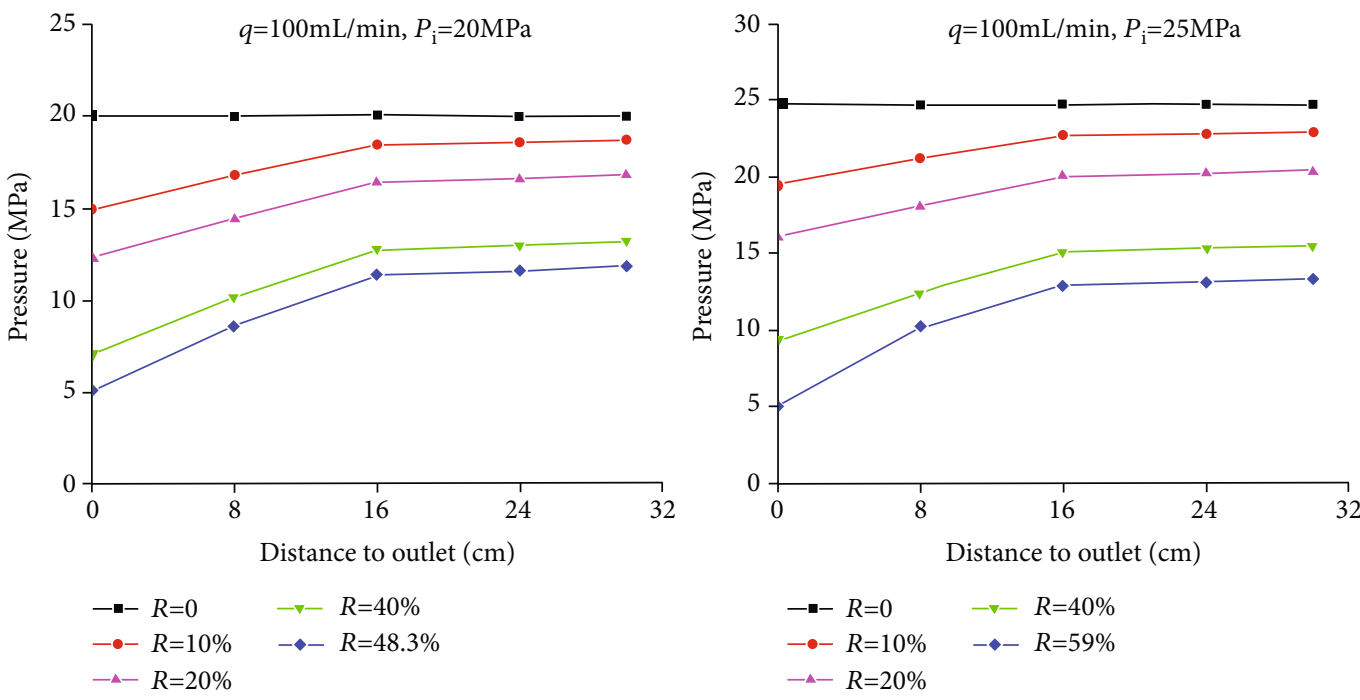

Figure 6: Comparisons of reservoir utilization in the Su3 core under different initial reservoir pressures.
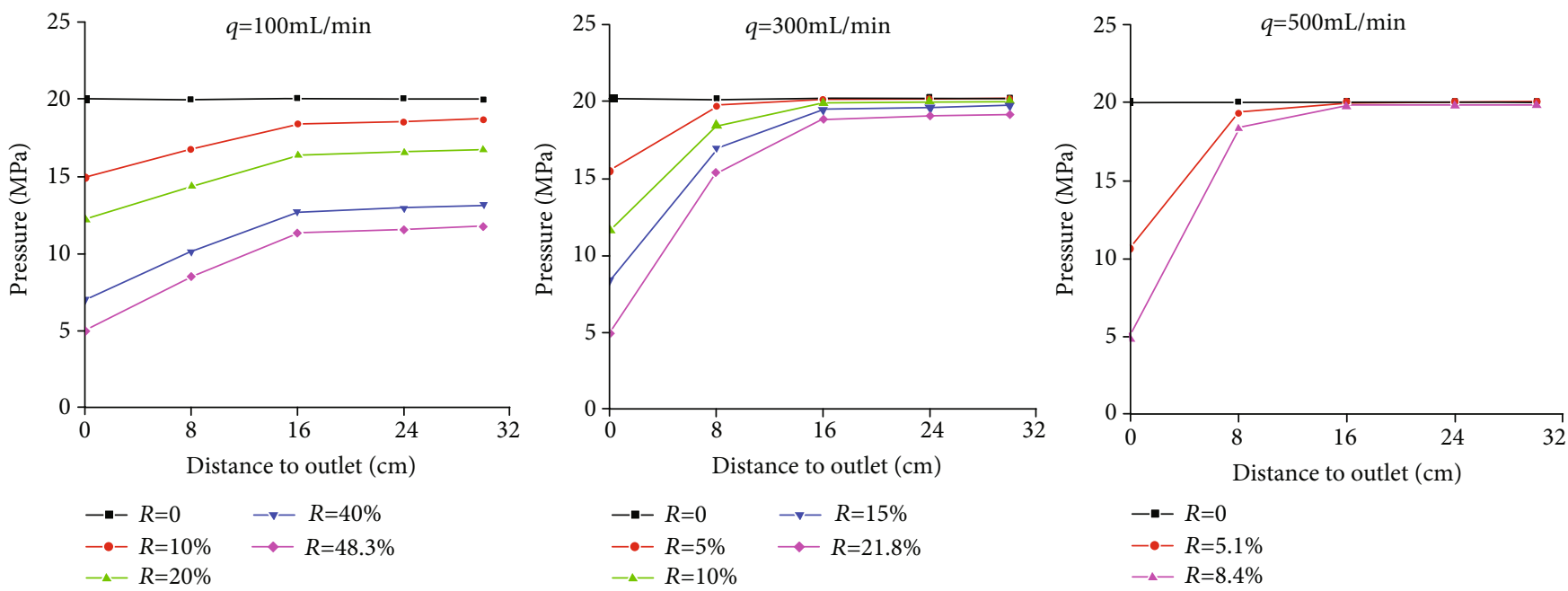

FIGURE 7: Comparisons of reservoir utilization in the Su3 core under different gas production rates.

4, and 5 were $13.27 \mathrm{MPa}, 13.03 \mathrm{MPa}, 12.87 \mathrm{MPa}, 10.17 \mathrm{MPa}$, and $5 \mathrm{MPa}$, respectively, and the drawdown pressure and the ultimate recovery were $8.27 \mathrm{MPa}$ and $59 \%$, respectively. Compared with the initial saturation pressure of $20 \mathrm{MPa}$, the ultimate recovery was increased by $10.7 \%$. This demonstrates that the greater the original pressure in tight sandstone reservoirs, the greater the elastic expansion energy that promotes the gas percolation. Therefore, the more gas that could be effectively utilized in the reservoir, and the greater the ultimate recovery.

3.3. Effect of Gas Production Rate. The gas production rate is an important parameter in the gas reservoir exploitation which can impact the productive life and the effective use of reservoir $[28,33]$. When the gas production rate was too high, the drawdown pressure would increase rapidly. Besides, the pressure at the core outlet would drop to the abandonment pressure when the experiment was conducted for a short time. When the experiment was in the abandoned con- ditions, the corresponding core inlet pressure was varied with different gas production rates. The higher gas production rate was significantly associated with lager drawdown and higher inlet pressure in abandonment conditions. As a result, the degree of reservoir utilization was very low, and the nonlinear pressure drop curve was stronger. The amount of produced gas was reduced, and the lower the ultimate recovery. As shown in Figure 7, the original pressure of the core was $20 \mathrm{MPa}$, and the gas production rate was $100 \mathrm{~mL} / \mathrm{min}$. When the experiment was carried out until $20.07 \mathrm{~min}$, the outlet pressure was reduced to the abandonment pressure, and the corresponding pressures of the pressure measuring points $1,2,3,4$, and 5 were $11.81 \mathrm{MPa}$, 11.59 $\mathrm{MPa}, 11.36 \mathrm{MPa}, 8.54 \mathrm{MPa}$, and $5 \mathrm{MPa}$, respectively. According to Equation (6), the corresponding recovery of each pressure point is $38.3 \%, 39.4 \%, 40.55 \%, 54.95 \%$, and $73.51 \%$, respectively, and the corresponding ultimate recovery at the gas production rate was $48.3 \%$. When the gas production rate was $500 \mathrm{~mL} / \mathrm{min}$, the experiment was carried out 

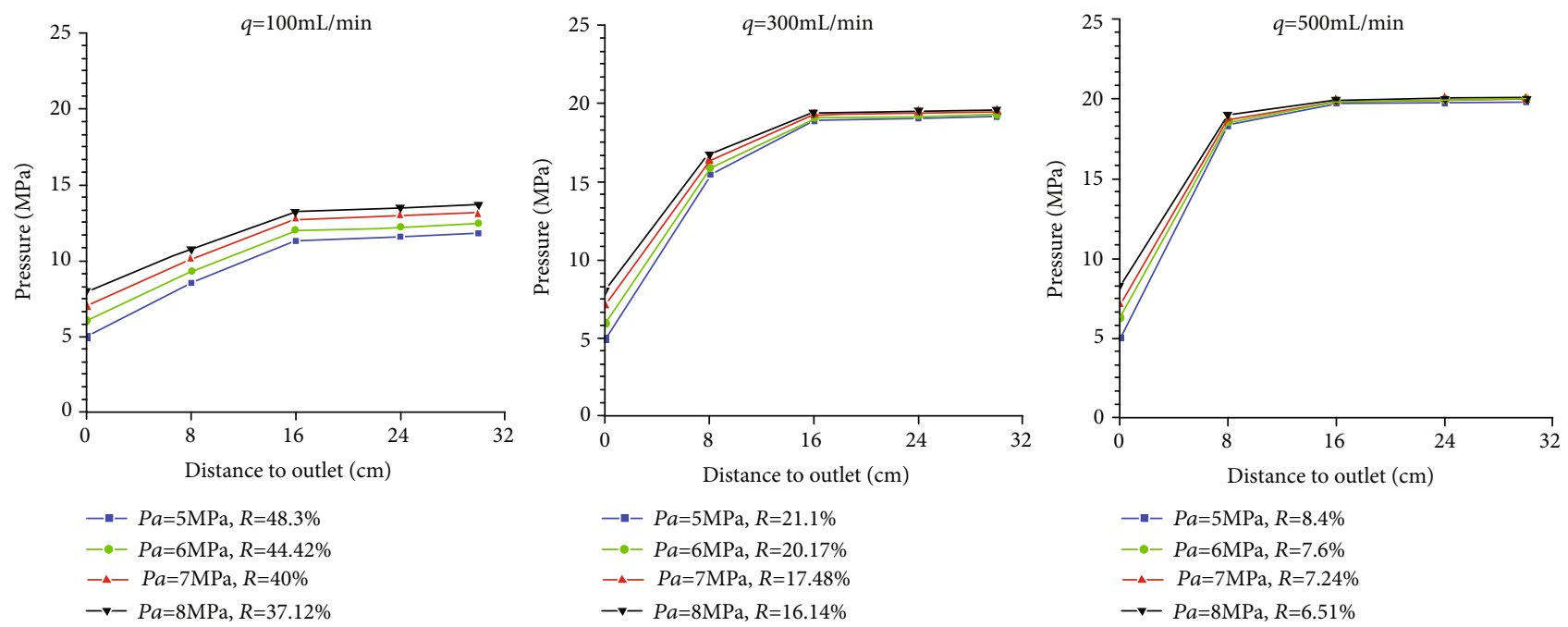

Figure 8: Drawdown curves of Su 3 under different abandonment pressure.

to $8 \mathrm{~min}$, and the outlet pressure was reduced to the abandonment pressure. The corresponding pressures of the pressure measuring points $1,2,3,4$, and 5 were $19.9 \mathrm{MPa}$, 19.88 $\mathrm{MPa}, 19.83 \mathrm{MPa}, 8.54 \mathrm{MPa}$, and $5 \mathrm{MPa}$, respectively. The reserves in the core end were basically not utilized, and the reservoir ultimate recovery was only $8.4 \%$.

3.4. Effect of Abandonment Pressure. The abandonment pressure plays a significant role in determining recovery efficiency, and the reservoirs with low permeability will have higher abandonment pressures than reservoirs with high permeability $[28,34]$. The characteristics of the drawdown curve under abandonment pressure reflected the distribution of remaining reserves. In this study, the abandonment pressure was uniformly set to $5 \mathrm{MPa}$; three abandonment pressures (6, 7 , and $8 \mathrm{MPa}$ ) were set to study the effect on the utilization of tight sandstone gas reservoir. Then, the recovery factor and the drawdown curves of Su 3 under different abandonment pressure were analyzed and compared.

Figure 8 shows the drawdown curves of the Su3 core with irreducible water at different gas production rates when the outlet pressure drops to the abandonment pressure. It can be seen from the pressure distribution curve that the drawdown curve was sharp near the outlet and was gentler away from the outlet when the experiment was carried out to the abandoned pressure condition. The trend of drawdown curves is similar at the same production rate but different abandonment pressure. However, the increased gas production rate would make this trend more apparent. The results of this phenomenon indicate that reserves near the core outlet can be better utilized, but the reserves near the core end are less utilized. The reason for the above phenomenon was that the pore pressure was gradually reduced during the tight sandstone depletion-drive development, and the pore pressure was different at different locations in the core. Therefore, the effective stresses at different points inside the core were different. However, there was a strong stress sensitivity in the tight sandstone, so the permeability of the core at different locations was different in the mining process. The effec- tive stress increased, and the permeability decreased along the seepage direction. In the case of constant flow condition, the drawdown pressure would gradually increase to ensure the gas supply, which was reflected in the drawdown curve.

3.5. Propagation Characteristic of the Moving Boundary. Pascal [11] and Liu [35] pointed out that there existed threshold pressure gradient in the low-permeability reservoirs. The propagation of pressure disturbances in the flow was not transmitted to infinity instantaneously like the highpermeability formation, but there existed a dynamic boundary which was the outer edge of the propagation of pressure disturbance. Tight sandstone gas reservoirs had similar dynamic boundary pressure propagation characteristics as low-permeability reservoirs. Analysis of gas reservoir pressure disturbance propagation could reflect the effective utilization range around gas wells, which was the theoretical basis for analyzing gas production performance.

Since there was the threshold pressure gradient in the tight sandstone gas reservoir, the pressure disturbance did not propagate to the end of the core instantaneously, while it would gradually move from the outlet end to the end of the core with the advance of time. As shown in Figure 9, the pressure wave propagated to pressure detecting points 4,3 , and 2, respectively, when the experiment was carried out for $6 \mathrm{~s}, 18 \mathrm{~s}$, and $34 \mathrm{~s}$, respectively, in the dry core, and it reached the core inlet when the time was $54 \mathrm{~s}$. The corresponding times of the dynamic boundary propagation to each pressure measurement point in the condition of irreducible water were $8 \mathrm{~s}, 24 \mathrm{~s}, 52 \mathrm{~s}$, and $92 \mathrm{~s}$, respectively. Within the influence range of the moving boundary, the reservoir was utilized and formed a pressure profile. However, the reservoir was not utilized outside the influence range of the moving boundary. The moving boundary gradually expanded with the advance of time, and the propagation speed increase first and then decrease. The higher the gas production rate was, the faster the dynamic boundary propagation speed was. The irreducible water in the core would increase the threshold pressure gradient of the reservoir, 

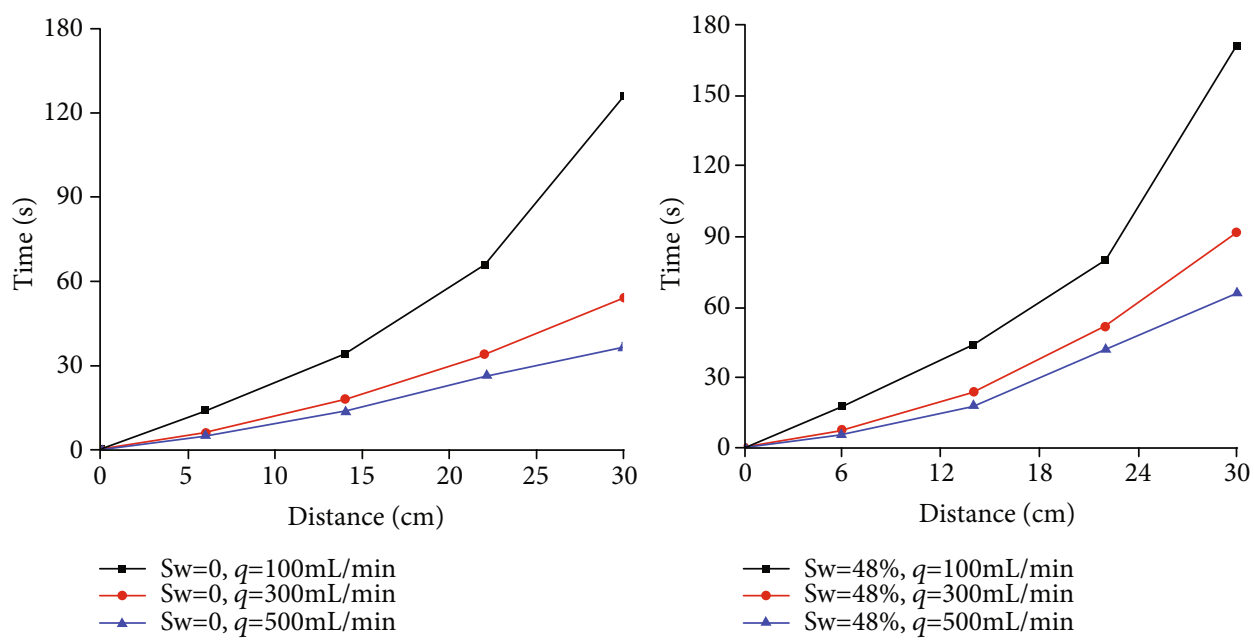

Figure 9: Time corresponding to the pressure drop propagated to each pressure measuring point in the Su3 core under the dry and bound water conditions.

which reduced the propagation velocity of the moving boundary and decreased the propagation velocity of the pressure disturbance. Therefore, the control area of a single well was limited in the tight reservoirs even if the formation was an infinite formation and there were no external boundary conditions.

\section{Similarity Conversion between Physical Experiment and Gas Well Production}

4.1. Similarity Criteria. Tight sandstone gas reservoirs are characterized by low permeability, and there is basically no natural productivity, and only after large-scale fracturing transformation can they obtain gas productivity $[36,37]$. However, the gas can only flow effectively within the fracturing-affected area, and thus fracturing technology is widely used during the development to increase the discharge area of the gas well and increase productivity [38]. When there was a fractured horizontal well in the center of the tight sandstone gas reservoir, the gas flowed from the reservoir to cracks and then flowed from the crack to the wellbore. And the cracks were the main discharge surface and vertical cracks were the main flow lines in the reservoir. The vertical cracks were formed after fracturing in the gas well, which was with equal spacing distribution and symmetrical distribution on both sides of the gas well, and the cracks had infinite flow conductivity, illustrated in Figure 10. Therefore, the percolation problem of the segmented fracturing of horizontal wells in tight sandstone reservoir could be simplified into several one-dimensional percolation models. Considering that cracks were distributed along the wellbore with equal spacing, the production dynamics between the cracks did not interfere, and then, the contribution of each crack to the gas well production was consistent.

Similarity criterion refers to the effective conversion relationship between physical model experiment parameters and mineral parameters established through similarity theory. The similarity criterion can realize the effective application of the physical simulation experiment results in the actual

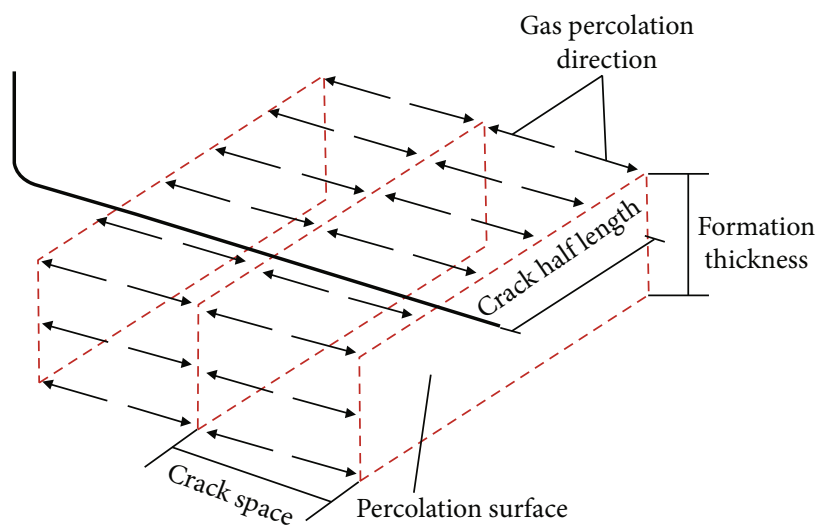

Figure 10: The fracturing flow field in the horizontal well.

mine field [39]. According to the percolation mechanics theory and gas reservoir engineering method, there are 13 independent variables and 1 dependent variable in the experiment, which contains 4 basic dimensions, as shown in Table 4. They are length dimension $(L)$, mass dimension $(M)$, time dimension $(T)$, and temperature dimension $(K)$, respectively. According to the similarity theory, there are 10 similarity numbers, and they can be expressed by the following form [40],

$$
\pi=K^{x_{1}} \phi^{x_{2}} S_{w}^{x_{3}} L^{x_{4}} R_{1}^{x_{5}} R_{2}^{x_{6}} P_{i}^{x_{7}} q^{x_{8}} t^{x_{9}} z^{x_{10}} T^{x_{11}} T_{s c}^{x_{12}} P_{s c}^{x_{13}} P_{5}^{x_{14}}
$$

According to the homogeneous principle, the corresponding linear equations are as follows:

$$
\begin{array}{r}
2 x_{1}+x_{4}+x_{5}+x_{6}-x_{7}+3 x_{8}-x_{13}-x_{14}=0, \\
x_{7}+x_{13}+x_{14}=0, \\
-2 x_{7}-x_{8}+x_{9}-2 x_{13}-2 x_{14}=0 \\
x_{11}+x_{12}=0 .
\end{array}
$$


TABle 4: Physical simulation similarity of the tight sandstone gas reservoir development.

\begin{tabular}{lcccc}
\hline No. & Similarity & Similar attribute & Model value & Mine value \\
\hline 1 & $\pi_{1}=\phi$ & Porosity & 0.11 & $0.02 \sim 0.15$ \\
2 & $\pi_{2}=S_{w}$ & Flow medium & 0.42 & $0.4 \sim 0.8$ \\
3 & $\pi_{3}=z$ & Gas compressibility & 1.055 & $0.9 \sim 1.2$ \\
4 & $\pi_{4}=T / T_{s c}$ & Temperature & 1 & $1.1 \sim 1.3$ \\
5 & $\pi_{5}=R_{2} / R_{1}$ & Geometric & 1 & $10 \sim 50$ \\
6 & $\pi_{6}=R_{2} / L$ & Geometric & 0.126 & $0.3 \sim 1$ \\
7 & $\pi_{7}=P_{s c} / P_{i}$ & Dynamic & 0.005 & $0.002 \sim 0.005$ \\
8 & $\pi_{8}=P_{a} / P_{i}$ & Dynamic & 0.250 & $0.1 \sim 1.0$ \\
9 & $\pi_{9}=q /\left(\pi R_{1} R_{2} K K_{r g} T_{s c} P_{i}^{2} / L \mu Z T P_{s c}\right)$ & Dynamic & 0.097 & $0.1 \sim 0.3$ \\
10 & $\pi_{10}=q t /\left(\pi R_{1} R_{2} L \phi S_{g} T_{s c} P_{i} / z T P_{s c}\right)$ & Recovery & 0.479 & $0 \sim 0.95$ \\
\hline
\end{tabular}

Equations (6), (7), (8), and (9) are homogeneous equations of length dimension, mass dimension, time dimension, and temperature dimension, respectively. The corresponding equations are homogeneous linear equations. According to the matrix theory, there are 10 basic solutions for homogeneous linear equations and 10 independent similarity criteria. By solving the equation, then conducting derivation and transformation, the similarity criterion of the similarity physical simulation experiment of tight sandstone gas reservoir development is obtained (as shown in Table 4).

$\pi_{1}$ and $\pi_{2}$ are the porosity and water saturation (or gas saturation), respectively; $\pi_{3}$ is the gas compressibility similarity, and the deviation factor of nitrogen and formation natural gas used in the experiment changes around 1, which is basically consistent; $\pi_{4}$ is the ratio of temperature to the standard temperature. The physical experiment temperature is $298.13 \mathrm{~K}$ and the formation temperature is $373.15 \mathrm{~K}$. The difference between the two and the standard temperature is small, and the similar criteria $\pi_{4}$ can be guaranteed to be basically consistent; $\pi_{5}$ and $\pi_{6}$ are the geometric similarity. In the physical experiment, $\pi_{5}$ is the ratio of the core long axis to the short half axis, which is generally 1 . In the field, $\pi_{5}$ is the ratio between the width of the fracture percolation surface and the thickness of reservoir. It can be seen from Table 4 that it is difficult to achieve consistency between physical experiment and the field according to the similarity criterion $\pi_{5}$, but it mainly represents the similarity of the vertical flow direction, which has little influence on the onedimensional flow in the experiment, and the similarity requirement can be appropriately reduced; $\pi_{7}$ and $\pi_{8}$ are the dynamic similarities, and they are similar initial pressure and similar abandonment pressure. The denominator of the similarity criteria $\pi_{9}$ is the expression of open flow capacity, which means that the ratio of the experimental production rate to the core open flow capacity should be consistent with the ratio of the field production and the gas well open flow capacity, which is consistent with the production of $1 / 3$ and $1 / 6$ based on the open flow capacity, and the significance of the similarity criteria $\pi_{9}$ is to establish relative production. The similarity criteria $\pi_{10}$ are the ratio of cumulative gas production to dynamic reserves, which reflects the degree of gas recovery. According to calculations and statistics, the compact gas reservoir prototype similarity criteria $\pi_{10}$ are between 0 and 0.6 , and the physical experiment $\pi_{10}$ is between 0 and 0.95 , and thus, the similarity criteria are basically the same. It can be seen from the comparison between the similarity criteria of the physical experiment and the actual value of the field in Table 4 that they are the same basically, and so, the dynamic physical experiment of tight gas reservoir development can basically realize the effective simulation of the field.

4.2. Similarity Conversion. According to the similarity criterion $\pi_{9}$, the velocity at the core outlet corresponds to the contribution of a single fracture to the gas well, which can be described as follows.

$$
q_{s c}=\frac{b h K K_{r g} T_{s c} P_{i}^{2}}{a \mu z T P_{s c}}\left(\frac{q L \mu z T P_{s c}}{\pi R_{1} R_{2} K K_{r g} T_{s c} P_{i}^{2}}\right)_{m},
$$

where the subscript $m$ is the experimental parameter.

Then, the horizontal well production is written as

$$
q=n_{f} q_{s c}
$$

Based on the similar criteria $\pi_{10}$ and the experimental time $t_{m}$, the actual production time in the field can be calculated as follows.

$$
t=\frac{b h a \phi S_{w} T_{s c} P_{i}}{q z T P_{s c}}\left(\frac{z T P_{s c} t_{m}}{\pi R_{1} R_{2} L \phi S_{w} T_{s c} P_{i}}\right) q_{m} .
$$

According to the similarity criteria $\pi_{8}$ and material model core pressure $P_{j}$, the pressure $P$ at different positions during the development process is calculated. Thus, the bottom hole pressure of gas well can be calculated based on the pressure at the outlet end of the physical model core.

$$
\mathrm{P}=P_{i}\left(\frac{P_{j}}{P_{i}}\right)_{m}
$$




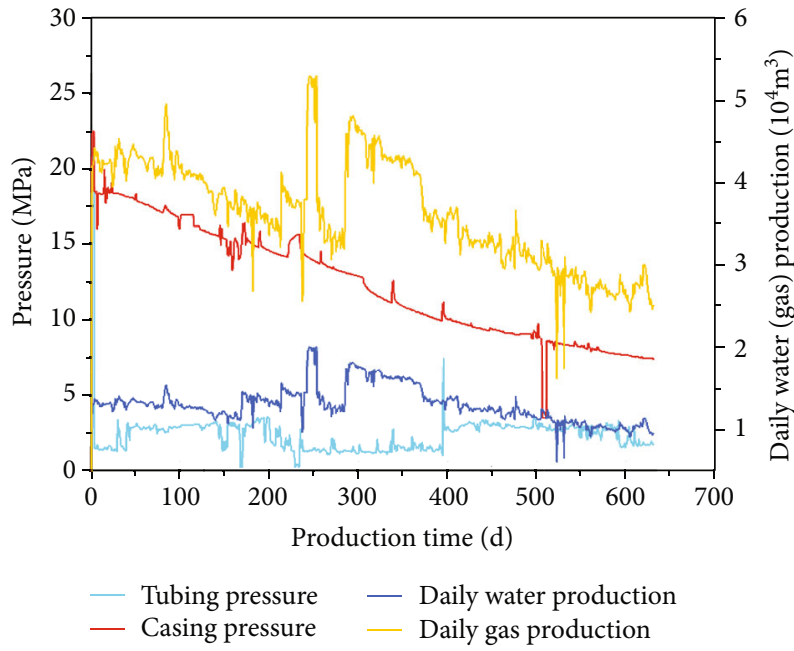

FIGURE 11: The production performance curve of Su-1 well.

4.3. Application of Similarity Criteria. To verify the accuracy of similarity criteria in the field, the Su-1 well of Sulige gas field was selected in this study, and they are similar in the reservoir characteristics. The original formation pressure of the reservoir is $29.23 \mathrm{MPa}$, and the reservoir thickness is $13.6 \mathrm{~m}$, and the porosity, the water saturation, and the reservoir temperature are $8.7 \%, 42 \%$, and $373.15 \mathrm{~K}$, respectively. The length of the horizontal well is $1045 \mathrm{~m}$, and the number of reconstruction sections is 8 , and the length of the fracture is $90 \mathrm{~m}$. Since April 2011, the production has started at $4.2 \times$ $10^{4} \mathrm{~m}^{3} / \mathrm{d}$ in the initial stage and gradually decreased to about $2.5 \times 10^{4} \mathrm{~m}^{3} / \mathrm{d}$ in the later stage. The average daily gas production is about $3.48 \times 10^{4} \mathrm{~m}^{3} / \mathrm{d}$, and there is a small amount of water in the process, and the related production performance is shown in Figure 11.

According to the similarity $\pi_{9}$, the average daily gas production of the Su- 1 well is $3.48 \times 10^{4} \mathrm{~m}^{3} / \mathrm{d}$, which corresponds to the experimental flow rate of $100 \mathrm{~mL} / \mathrm{min}$. Based on the experimental result and the similarity criteria, the production performance curve can be calculated as shown in Figure 12 . From the result of Figure 12, it can be seen that the production performance curve calculated by the experimental result and the similarity criterion is basically consistent with the actual gas production performance curve in the field. There exists a slight deviation, and the reason is that the influence of the fracture conductivity, the wellbore flow, and other production factors are not considered. Thus, the production prediction of gas reservoir development can be carried out based on similar criteria and the physical experiments.

\section{Conclusions}

The variation law of reserve utilization in tight sandstone gas reservoirs development was studied using the multipoint embedded measurement system, and the effects of the utilization of reservoir were analyzed. Besides, the effective conversion relationship between the physical experiment and the actual field production was established by the dimensional analysis. The conclusions are as follows:

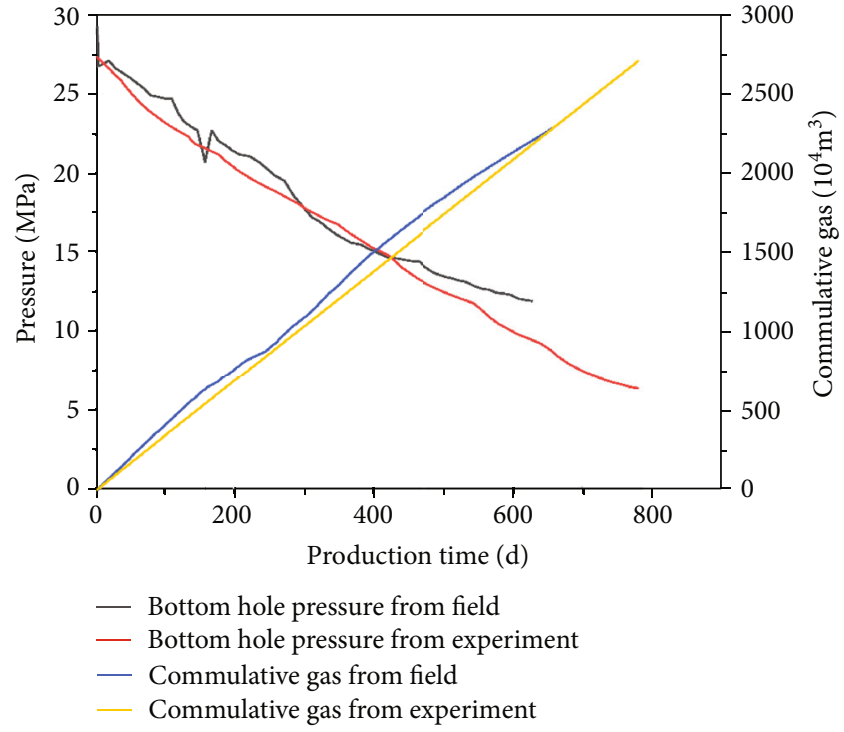

FIGURE 12: Model experiment and similarity transformation results of Su-1 well.

(1) The multipoint embedded measurement system can accurately measure the pressure changes at different positions on the core section during the gas reservoir development. Selected $30 \mathrm{~cm}$ long core can weaken the effect of end surface and overcome the unreality of splicing long cores, and the experimental results are more representative of real reservoirs.

(2) The water cut of tight sandstone gas reservoir has an impact on the gas flow characteristics and thus reduces the ultimate recovery. The lower the permeability is, the higher the effect of water on the reservoir utilization is, which is reflected in the drawdown curve as the drawdown curve is nonlinearly enhanced. The higher the reservoir pressure is, the lower the gas production rate is, and the smoother the drawdown curve is and the higher the ultimate utilization of the reservoir is.

(3) There exists a moving boundary effect in the development of tight gas reservoirs. The velocity of the moving boundary becomes large and then reduces smaller, and the moving boundary will gradually expand with time. The water cut in the reservoir will reduce the velocity of the moving boundary.

(4) Based on the similarity theory, the production performance curve calculated by the experimental result is basically consistent with that in the field. However, there exists a slight deviation between them as a result of the effects of the fracture conductivity, the wellbore flow, and other production factors.

\section{Data Availability}

The data used to support the findings of this study are available from the first author upon request. 


\section{Conflicts of Interest}

The authors declare that there are no conflicts of interest regarding the publication of this paper.

\section{Acknowledgments}

This work is financially supported by the project of the National Natural Science Foundation of China (Nos. U1762216 and 11802312), National Science and Technology Major Project of the Ministry of Science and Technology of China (No. 2017ZX05030003), and Scientific Research and Technology Development Project of China National Petroleum Corporation (No. 2019B-1507). We thank the support from the Youth Foundation of Key Laboratory for Mechanics in Fluid Solid Coupling Systems, Chinese Academy of Sciences.

\section{References}

[1] W. Wang, Y. Jiang, R. Swennen, J. Yuan, J. Liu, and S. Zhang, "Utility of inclusions for interpreting reservoir thresholds for tight sandstone gas accumulation in the Longfengshan and Dongling sags, Southeast China," Journal of Natural Gas Science and Engineering, vol. 61, pp. 270-283, 2019.

[2] A. G. Oluwadebi, K. G. Taylor, and L. Ma, "A case study on 3D characterisation of pore structure in a tight sandstone gas reservoir: the Collyhurst Sandstone, East Irish Sea Basin, northern England," Journal of Natural Gas Science and Engineering, vol. 68, p. 102917, 2019.

[3] B. Dong, M. Meng, Z. Qiu, Z. Lu, Y. Zhang, and H. Zhong, "Formation damage prevention using microemulsion in tight sandstone gas reservoir," Journal of Petroleum Science and Engineering, vol. 173, pp. 101-111, 2019.

[4] X. Z. Li, Z. GUO, Y. WAN et al., "Geological characteristics and development strategies for Cambrian Longwangmiao formation gas reservoir in Anyue Gas Field, Sichuan Basin, SW China," Petroleum Exploration and Development, vol. 44, no. 3, pp. 428-436, 2017.

[5] J. Zhang, X. Li, W. Shen et al., "Study of the effect of movable water saturation on gas production in tight sandstone gas reservoirs," Energies, vol. 13, no. 18, p. 4645, 2020.

[6] K. Xie, X. Lu, H. Pan et al., "Analysis of dynamic imbibition effect of surfactant in microcracks of reservoir at high temperature and low permeability," SPE Production \&Operations, vol. 33, no. 3, pp. 596-606, 2018.

[7] W. J. Shen, F. Q. Song, X. Hu, G. M. Zhu, and W. Y. Zhu, "Experimental study on flow characteristics of gas transport in micro- and nanoscale pores," Scientific Reports, vol. 9, article 10196, no. 1, 2019.

[8] Z. Sun, X. Li, W. Liu, T. Zhang, M. He, and H. Nasrabadi, "Molecular dynamics of methane flow behavior through realistic organic nanopores under geologic shale condition: pore size and kerogen types," Chemical Engineering Journal, vol. 398, p. 124341, 2020.

[9] M. Q. Wei, Y. G. Duan, M. Z. Dong, Q. T. Fang, and M. Dejam, "Transient production decline behavior analysis for a multifractured horizontal well with discrete fracture networks in shale gas reservoirs," Journal of Porous Media, vol. 22, no. 3, pp. 343-361, 2019.
[10] H. Zhang, Y. Zhong, E. Kuru, J. Kuang, and J. She, "Impacts of permeability stress sensitivity and aqueous phase trapping on the tight sandstone gas well productivity - a case study of the Daniudi gas field," Journal of Petroleum Science and Engineering, vol. 177, pp. 261-269, 2019.

[11] H. Pascal, "Nonsteady flow through porous media in the presence of a threshold gradient," Acta Mechanica, vol. 39, no. 3-4, pp. 207-224, 1981.

[12] W. G. Feng and J. L. Ge, "Single medium, the double medium unsteady seepage Darcy velocity," Petroleum Exploration and Development, vol. 12, no. 1, pp. 56-62, 1985.

[13] R. A. Wattenbarger, A. H. El-Banbi, M. E. Villegas, and J. B. Maggard, "Production analysis of linear flow into fractured tight gas wells," in Proceedings of SPE Rocky Mountain Regional/Low-Permeability Reservoirs Symposium, pp. 1-12, Denver, Colorado, 1998.

[14] Y. E. Deng and C. Q. Liu, "Mathematical model of nonlinear flow law in low permeability porous media and its application," Acta Mechanica Sinica, vol. 30, no. 4, pp. 72-77, 2001.

[15] B. Z. Hsieh, G. V. Chilingar, and Z. S. Lin, "Propagation of radius of investigation from producing well," Energy Sources, Part A: Recovery, Utilization, and Environmental Effects, vol. 29, no. 5, pp. 403-417, 2007.

[16] G. Q. Feng, Q. G. Liu, G. Z. Shi, and Z. H. Lin, “An unsteady seepage flow model considering kickoff pressure gradient for low-permeability gas reservoirs," Petroleum Exploration and Development, vol. 35, no. 4, pp. 457-461, 2008.

[17] X. D. Wang, X. C. Hou, M. Q. Hao, and T. Yang, "Pressure transient analysis in low-permeable media with threshold gradients," Acta Mechanica Sinica, vol. 32, no. 5, pp. 847-851, 2011.

[18] B. Y. Ji and Y. F. He, "Formation pressure distribution of a single well based on low-velocity non-Darcy flow," Acta Mechanica Sinica, vol. 32, no. 3, pp. 466-469, 2011.

[19] M. Nobakht and C. R. Clarkson, "A new analytical method for analyzing linear flow in tight/shale gas reservoirs: constantflowing-pressure boundary condition," SPE Reservoir Evaluation \& Engineering, vol. 15, no. 3, pp. 370-384, 2013.

[20] M. Nobakht and C. R. Clarkson, "A new analytical method for analyzing linear flow in tight/shale gas reservoirs: constantrate boundary condition," SPE Reservoir Evaluation \& Engineering, vol. 15, no. 1, pp. 51-59, 2013.

[21] S. Huang, Y. D. Yao, R. Y. Ma, and J. W. Wang, "Analytical model for pressure and rate analysis of multi-fractured horizontal wells in tight gas reservoirs," Journal of Petroleum Exploration and Production Technology, vol. 9, pp. 383-396, 2018.

[22] H. U. Yong, L. I. Xizhe, Y. WAN et al., "Physical simulation on gas percolation in tight sandstones," Petroleum Exploration and Development, vol. 40, no. 5, pp. 621-626, 2013.

[23] Q. N. Yu, Y. K. Liu, S. Liang, X. Liu, D. Yao, and Y. Yu, "Experimental study on seepage flow patterns in heterogeneous lowpermeability reservoirs," Journal of Petroleum Exploration and Production Technology, vol. 8, no. 2, pp. 589-596, 2018.

[24] M. G. Lewis, M. M. Sharma, H. H. Dunlap, and M. H. Dorfman, "Techniques for measuring the electrical properties of sandstone cores," in Proceedings of SPE Annual Technical Conference and Exhibition, pp. 1-7, Houston, Texas, 1988.

[25] H. S. Han, S. Li, D. S. Ma, Z. M. Ji, H. W. Yu, and X. L. Chen, "Investigation of flue gas displacement and storage after the water flooding in a full diameter conglomerate long-core," 
Petroleum Exploration and Development, vol. 45, no. 5, pp. 847-852, 2018.

[26] X. L. Li, Z. Q. Li, P. Guo, H. C. Li, and X. S. Li, "Long core physical simulation for $\mathrm{CO}_{2}$ miscible displacement," Petroleum Exploration and Development, vol. 31, no. 5, pp. 102-104, 2004.

[27] D. W. Meng, A. L. Jia, G. Ji, and D. B. He, "Water and gas distribution and its controlling factors of large scale tight sand gas fields: a case study of western Sulige gas field, Ordos Basin, NW China," Petroleum Exploration and Development, vol. 43, no. 4, pp. 663-671, 2016.

[28] T. Ahmed, "Reservoir Engineering Handbook," in Gulf Professional Publishing, Imprint Elsevier, Oxford, UK, 4th edition, 2010.

[29] R. J. Schilthuis, "Active oil and reservoir energy," Transactions of the AIME, vol. 118, no. 1, pp. 33-52, 2013.

[30] C. S. Kabir, B. Parekh, and M. A. Mustafa, "Material-balance analysis of gas and gas-condensate reservoirs with diverse drive mechanisms," Journal of Natural Gas Science and Engineering, vol. 32, pp. 158-173, 2016.

[31] X. H. Ma, A. Jia, J. Tan, and D. B. He, "Tight sand gas development technologies and practices in China," Petroleum Exploration and Development, vol. 39, no. 5, pp. 572-579, 2012.

[32] X. M. Xiao, B. Q. Zhao, Z. L. Thu, Z. G. Song, and R. W. T. Wilkins, "Upper Paleozoic petroleum system, Ordos Basin, China," Marine and Petroleum Geology, vol. 22, no. 8, pp. 945-963, 2005.

[33] L. A. Høyl, P. Papatzacos, and S. M. Skjaevel, "Critical rate for water coning: correlation and analytical solution," SPE Reservoir Evaluation \& Engineering, vol. 4, pp. 495-502, 1989.

[34] J. J. Arps, "Estimation of primary oil reserves," Petroleum Transactions, AIME, vol. 207, pp. 182-191, 1956.

[35] C. Q. Liu, "Approximate solution of a starting gradient ratio consolidation problem," Chinese Journal of Geotechnical Engineering, vol. 4, no. 3, pp. 107-109, 1982.

[36] J. DAI, N. I. Yunyan, and W. U. Xiaoqi, "Tight gas in China and its significance in exploration and exploitation," Petroleum Exploration and Development, vol. 39, no. 3, pp. 277284, 2012.

[37] X. Z. Li, X. H. Liu, Y. H. Sun et al., "Correlation between perwell average dynamic reserves and initial absolute open flow potential (AOFP) for large gas fields in China and its application," Petroleum Exploration and Development, vol. 45, no. 6, pp. 1088-1093, 2018.

[38] M. Vishkai and I. Gates, "On multistage hydraulic fracturing in tight gas reservoirs: Montney Formation, Alberta, Canada," Journal of Petroleum Science and Engineering, vol. 174, pp. 1127-1141, 2019.

[39] Sedov, Similar methods and dimension theory in mechanics, Science Press, Beijing, China, 1982.

[40] J. Worstell, "Mechanical/physical examples of dimensional analysis," in Dimensional Analysis, Elsevier Inc, Oxford, UK, 2014. 